Arqueología y Sociedad,

№ 22, 2010

\title{
LA Ley de Memoria Histórica Y LA BÚSQUEDA DE LOS DESAPARECIDOS EN ESPAÑA: UNA APROXIMACIÓN DESDE LA ARQUEOLOGÍA FORENSE
}

Aldo Bolaños*

\section{Resumen}

La Ley de Memoria Histórica en España (Ley 52/2007, de 26 de diciembre) tiene la intención de abrir el camino a miles de españoles víctimas de la guerra civil y de la dictadura franquista (1939 - 1975) a ser reparadas moral y económicamente y además, permitir a la búsqueda y la devolución a sus familiares de los restos mortales de aquellos que desaparecieron forzadamente o que fueron ejecutados extrajudicialmente. Sin embargo, hay un gran debate acerca de la si la Ley, tal como está planteada actualmente, puede ayudar especialmente a lograr este último fin.

En el artículo se discute acerca de la forma en que los procedimientos científicos de la arqueología forense son abordados por la Ley, en unos casos limitándolos, y cómo se fijan las responsabilidades del Estado Español respecto a asumir la problemática de las familias y de las miles de fosas que aun quedan sin dignificar en el territorio español.

El artículo busca reflexionar, indirectamente, desde el análisis de la Ley de Memoria Histórica española, acerca de la problemática de los aproximadamente 15 mil desaparecidos que dejó el conflicto interno peruano y en la que aun no hemos desarrollado un proceso político, jurídico-legal, humanitario y científico acorde al reclamo de los familiares por recuperar a sus seres queridos y a la necesidad del Perú de dignificar sus paisajes, es decir, paisajes sin fosas comunes

Palabras clave

Ley de Memoria Histórica, Arqueología forense, desaparecidos España, desaparecidos Perú, Memoria.

\begin{abstract}
The Law of Historical Memory in Spain (Law 52/2007 of 26 December) is intended to pave the way for thousands of victims of the Spanish civil war and Franco's dictatorship (1939-1975) to be morally and economically repaired and also enable the search and return to their relatives in the remains of those forcibly disappeared or were executed extra-judicially. However, there is great debate about whether the Act, as currently posed, can help.

The article discusses how the scientific procedures of forensic archeology are addressed by the Act, in some cases limiting it, and how to fix the Spanish state's responsibilities to reach solutions for the problems of families and thousands from graves still left without dignity in Spanish territory.

The essay reflects, indirectly, from the analysis of the Spanish Law of Historical Memory, about the problems of the approximately 15,000 missing persons who left the Peruvian internal conflict in which we have not yet developed a political process, legal-legal, humanitarian and scientific according to the claim of the relatives to recover their loved ones and the Peru's need to dignify their landscapes, ie landscapes without mass graves.
\end{abstract}

\section{Keywords}

Law of Historical Memory, Forensic Archaeology, Missing Spain, Missing Perú, Memory.

* Arqueólogo. Miembro fundador de la Asociación Latinoamericana de Antropología Forense - ALAF y Miembro Fundador del Equipo Peruano de Antropología Forense - EPAF.

Correo electrónico: aldofernando@yahoo.com 


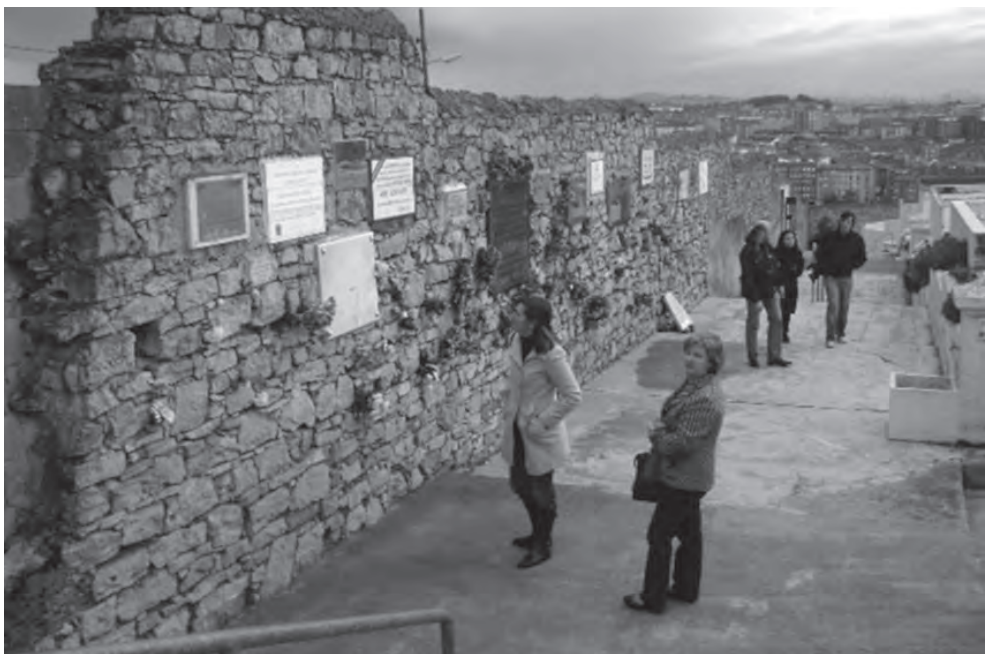

Figura 1. Pared de fucilamiento de víctimas de la dictadura franquista. Cementerio de Ceares, Gijón, Asturias, España.

La búsqueda de los desaparecidos tiene que cumplir requisitos imprescindibles a fin de desarrollar estrategias firmes que conduzcan a la ubicación de las víctimas y a la satisfacción de los familiares que buscan los restos mortales de sus parientes. Como es obvio, no se puede crecer como país, sin conocer la verdad histórica de víctimas de desaparición forzada y ejecución extrajudicial oculta en las fosas comunes de campos y cementerios.

En España, la Ley de Memoria Histórica (Ley 52/2007, de 26 de diciembre) ha abierto el camino de miles de familias a ser reparadas moral y económicamente y además, a la búsqueda y la devolución de los restos mortales de sus seres queridos. Sin embargo, hay un gran debate acerca de si la Ley, tal como está planteada puede ayudar a este último fin. A continuación se presentan una serie de reflexiones ${ }^{1}$ a fin de contribuir a ampliar esta Ley que sigue planteando controversia y lucha en la sociedad española.

1 Se trata de incorporar las perspectivas recogidas en el contacto con las experiencias latinoamericanas de búsqueda de desaparecidos, de las tareas que en el Perú, tierra del autor, se plantean al respecto y también desde las experiencias desarrolladas como parte de los equipos forenses que recolectaron las evidencias arqueológicas forenses para el Tribunal Internacional para la Ex Yugoslavia -ICTY, en los Balcanes a fines del milenio pasado e inicios del presente.
Este artículo se organiza en dos grupos de conceptos previos: en primer lugar, la definición de lo que es arqueología forense y su organización básica para emprender la búsqueda de un modo sistemático e integral; en segundo lugar, los elementos de planificación que siempre deben estar presentes para hacer eficaz la búsqueda de las víctimas.

\section{BÚSQUEDA DE LOS DESAPARECIDOS Y ARQUEOLOGÍA FORENSE ${ }^{2}$}

La búsqueda de los desaparecidos mediante la arqueología forense se desarrolla en cuatro etapas fundamentales: a) la investigación preliminar; b) la intervención arqueológica forense; c) el acompañamiento del regreso de los restos mortales con sus familias y la sociedad y d) la interpretación histórica y social de los hechos investigados.

2 La arqueología forense engloba el conjunto de actuaciones requeridas en la búsqueda de las personas desaparecidas. Investiga los crímenes pasados a partir de los restos materiales dejados por sus autores y utiliza las técnicas de recuperación y estudio de materiales arqueológicos en los análisis y reconstrucción de las escenas de crimen. Concurren a ella otras aplicaciones científicas que permiten un mejor conocimiento de los hechos investigados como la antropología física o la genética $(\mathrm{ADN})$ en la identificación de las víctimas y la determinación de causas y formas de muerte. 
Los contenidos de cada una de las fases mencionadas incluyen:

a) La investigación preliminar: la documentación, identificación, verificación y evaluación de los casos y de los lugares de entierro o de destrucción de los restos; se incluyen el desarrollo de los sistemas, métodos, técnicas e instrumentos para la realización de búsquedas en universos complejos de personas desaparecidas o ejecutadas extrajudicialmente.

b) La intervención arqueológica forense: consiste en la recuperación de los restos mortales de las víctimas y de las escenas criminales, principalmente mediante las exhumaciones y aplicación de métodos arqueológicos de excavación y registro; la identificación antropológica física mediante el trabajo de morgue y de laboratorio, el establecimiento de las causas y formas de muerte. Esta etapa termina, cuando es posible, en la devolución de la identidad que le fue robada a la víctima; incluye la intervención genética.

c) El acompañamiento familiar y social: es el acto de devolución de las víctimas a sus familiares y a la sociedad así como el acompañamiento en el entierro. En caso no se logre localizar el cuerpo, permite cumplir con el derecho a saber estipulado por el Comité Internacional de la Cruz Roja. Se incluye el acompañamiento posterior que se da en los procesos judiciales, el cual puede durar años, especialmente cuando los restos identificados son parte de las pruebas judiciales para sentenciar a los perpetradores de los crímenes.

d) La interpretación histórica y social: se completa cuando se cumplen las fases anteriores y son parte del compromiso ético del investigador con la sociedad, con su ciencia y con su tiempo. Cumplida esta etapa se regresa nuevamente a la fase de inicio, a la investigación preliminar, en el afinamiento de los sistemas de búsqueda a partir de las nuevas comprensiones desarrolladas. El arqueólogo forense no es un simple "exhumador", es un investigador social.

\section{Elementos Básicos EN LA BÚSQUEDA DE LOS DESAPARECIDOS}

Todo el sistema de búsqueda de personas desaparecidas se debiera construir desde la lógica de que es el Estado, en este caso el español, el responsable principal de encabezar esta tarea y que es la sociedad civil la encargada de vigilar y participar en la realización de este proceso de modo transparente e independiente. A partir de estos criterios y a fin de propiciar el uso de todo el potencial de la Ley de Memoria Histórica, la búsqueda de personas desaparecidas por conflicto interno debería tener siempre los siguientes componentes:

a. El Estado está obligado a dotarse de un plan general de búsqueda de las personas desaparecidas que permita establecer metas cuantitativas y temporales aproximadas, proponiendo plazos para la aproximación máxima a la solución del problema.

b. El plan de búsqueda debe permitir combinar cuatro marcos o columnas fundamentales para garantizar su funcionamiento y sostenibilidad: el marco político, el marco humanitario, el marco judicial y el marco científico ${ }^{3}$. El plan y sus programas derivados, se conciben a partir de la acción conjunta y coordinada de las instancias de la sociedad civil con las de las entidades del gobierno, de la justicia

3 El marco político incluye la responsabilidad del Estado en la búsqueda de las víctimas expresado en un orden jurídico e institucional en cumplimiento de las normas internacionales de los derechos humanos y del derecho humanitario; el marco humanitario es la satisfacción plena de los afectados (los familiares son víctimas también) mediante la principal reparación: la explicación oficial de qué pasó con su familiar y la devolución de sus restos mortales como parte de un programa de actuación estatal al margen de los intereses favorables o no de determinados sectores sociales o políticos (la típica posición de no exhumar para no "abrir heridas" como condicionante de la acción humanitaria); el marco judicial incluye los aspectos relativos a la investigación de casos y sentencias, prescripción de casos, tratamiento de las evidencias criminales y desarrollo de plazos de investigación acordes al proceso humanitario y científico; el marco científico debe garantizar la calidad de la investigación, su imparcialidad y la integridad física de la evidencia. 
nacional y las instancias académicas y profesionales públicas y privadas.

c. La búsqueda de personas desaparecidas producto de una violación sistemática, masiva y prolongada de sus derechos humanos no puede ser hecha persona por persona sino deben desarrollarse partir de universos de víctimas y conjuntos de casos asociados. Las víctimas no siempre están adonde se supone o dicen que están sino que su destino puede variar en el conjunto de sitios de entierros en función a los distintos episodios y escenarios de la violencia (local, regional, nacional).

d.La búsqueda de personas desaparecidas obliga a desarrollar instrumentos metodológicos que a partir del establecimiento de los patrones de desaparición forzada y ejecución extrajudicial, permitan:

- Garantizar la preservación de la memoria biológica y social de las víctimas con fines de identificación antropológica y de judicialización ante su eventual hallazgo en cualquier momento.

- Facilitar la ubicación de las víctimas y los escenarios de crimen.

- Facilitar su identificación antropológica física.

e. Para estas tareas el instrumento principal es la generación de una base de datos arqueológicos forenses especializada, desarrollada a partir de cuatro componentes básicos: la base de datos Antemortem, la base de datos de sitios de entierro, la base de datos de estudios antropológicos físicos, la base de datos de documentación complementaria. En realidad, no basta con un "mapa de fosas" sino se requieren, más bien, mapas de búsqueda o "mapas inteligentes" a partir del desarrollo de sistemas de información geográfica especializados. Estos mapas sirven igualmente para las labores administrativas del Estado respecto a su protección o intervención.

f. Los arqueólogos forenses, en la medida que intervienen sobre evidencias de crímenes no declarados expresamente como prescri- tos en forma individual o como parte de un conjunto de casos individuales, debe contar siempre con la autorización y presencia de un fiscal o de un juez con temor de que ante su ausencia, puedan ser acusados de alteración o destrucción de la evidencia. Este punto debe ser debatido en función al estado de la judicialización de los casos en España y definido por las autoridades judiciales, sin embargo, es necesario que los arqueólogos tomen las previsiones legales a este respecto a fin de evitar denuncias en su contra.

g. El "plan general de búsqueda de personas desaparecidas" es la guía maestra principal. De este plan debe derivarse el sistema de búsqueda a partir de los instrumentos metodológicos mencionados y también el "plan de intervenciones arqueológicas forenses". Este último plan debería contar con un rol de intervenciones de emergencia que abarque todo el universo de sitios de entierro, con niveles de verificación avanzado o con riesgos de conservación y emergencia. Al mismo tiempo, se debe ir avanzando en la documentación de los nuevos casos que conformen los planes de intervención de mediano y largo plazo ${ }^{4}$. Finalmente, el protocolo de exhumaciones es el último eslabón de la cadena de manuales y protocolos, junto a aquellos que se utilizan para cada una de las ramas de la ciencia que intervienen en la investigación. Por lo general, estos protocolos ya existen y son parte de estándares científicos internacionales aprobados y de lo que se trata es de adaptarlos a las formas administrativas locales.

h. El impulso de las acciones anteriores debe ser contemplado como parte de una Oficina de Búsqueda de Personas Desaparecidas ${ }^{5}$, autónoma e independiente, la cual debería

4 No se incluye el concepto de casos paradigmáticos en los elementos de priorización pues todos los casos, para los familiares, son de igual importancia.

5 Las Naciones Unidas desarrollaron esta experiencia en Kosovo con la creación en el 2002 de la Oficina para Personas Desaparecidas y ciencias Forenses. 


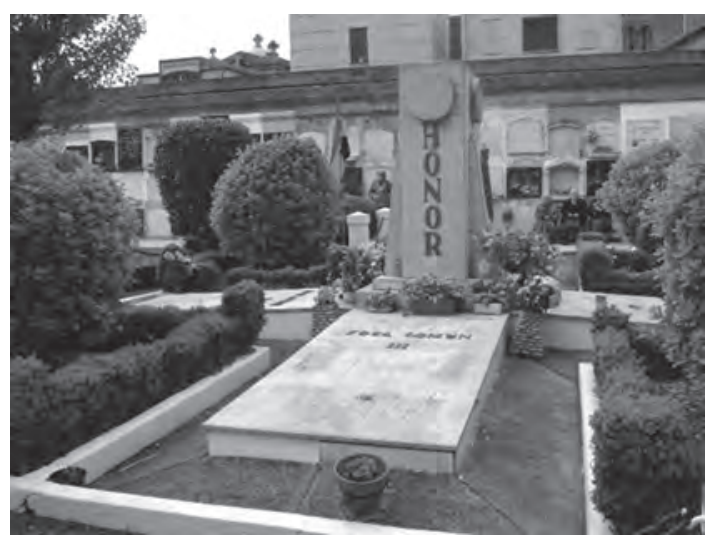

Figura 2. Fosa Común III en el cementerio de Ceares, Gijón, Asturias, España. Se estima que hay enterradas más 1400 vícimas del franquismo en el cementerio.

estar inmersa a su vez en una dependencia de atención general a las víctimas y familiares, esta última, ya planteada en el Plan de Derechos Humanos del actual gobierno.

Considerando los criterios anteriores como elementos necesarios para potenciar el uso de la Ley de Memoria Histórica y realizar de modo eficiente y eficaz la búsqueda de los desaparecidos españoles, se plantea la pregunta siguiente: ise incluyen estos criterios en la actual Ley?

\section{La Ley de Memoria Histórica y la BÚSQUEDA DE LAS PERSONAS DESAPARECIDAS}

Los aspectos arqueológicos forenses de la búsqueda de los desaparecidos se organizan a partir de tres temas fundamentales en la Ley Memoria Histórica: a) Los archivos y la documentación referida a hechos históricos y a las víctimas del conflicto; b) el papel de las instituciones públicas, la elaboración de planes y los aspectos administrativos y c) las exhumaciones y los mapas de fosas.

La Ley de Memoria Histórica reconoce el derecho individual a la memoria personal y familiar, pero limita este derecho a los registros y documentos de carácter público. Por un lado, muchas de las víctimas descansan en los cementerios de la iglesia católica -icon su consenti- miento o el de sus familias?- encontrándose hoy los documentos y archivos principales para su hallazgo en manos privadas. Los familiares de las víctimas y los investigadores dependen de la iglesia católica para poder acceder a parte de los archivos y saber si las víctimas se encuentran allí enterradas o en qué fosa o nicho fueron a parar. Por otro lado, las víctimas en fosas comunes fuera de los cementerios no están en ningún archivo público u oficial y su búsqueda se hace principalmente en base a testimonios de testigos y de archivos oficiales pero no siempre públicos (archivos militares por ejemplo).

Ante esta necesidad se requiere ampliar la Ley incluyendo a los archivos privados cuando se suponga su uso en investigaciones que permitan la ubicación e identificación de personas desaparecidas. Estos archivos, privados pero de interés público, debieran también ser considerados Bienes de Interés Cultural, parte del Patrimonio Cultural de la Nación (Ley de Patrimonio Histórico 16/1985 y sus modificatorias), por su importancia histórica y el necesario acceso de los investigadores y personas interesadas. Ambas situaciones plantean caminos largos para su solución.

Si bien la Ley de Memoria Histórica deja saber que el Estado español ha tomado conocimiento de la existencia de fosas individuales o colectivas en su territorio y de ciudadanos y ciudadanas españolas presuntamente allí enterrados, la Ley no está totalmente adecuada a las normas internacionales en esta materia. Las Naciones Unidas en la Declaración sobre la Protección de Todas las Personas contra las Desapariciones Forzadas aprobada por la Asamblea General en su resolución 47/133 de 18 de diciembre 1992 y en otras posteriores, establece la obligación de los Estados a la búsqueda de las personas desaparecidas en su territorio.

A pesar de esto, la Ley (Artículo 11.1) delega la responsabilidad de la exhumación de las víctimas básicamente en los familiares al decir que primero éstos deben solicitarlo y luego, recién las instituciones públicas deberán desarrollar planes para su exhumación. Si bien así 
se soluciona con toda justicia el problema individual de una familia o de pequeños grupos de personas que conocen el paradero de sus parientes, es necesario profundizar la medida de modo que se pueda satisfacer el derecho de todas las víctimas, las no identificadas o no reclamadas por nadie, a ser enterradas en un cementerio. España y cualquier otro país con este problema, le debe a cada familia una explicación de qué pasó con sus desaparecidos.

Hay aquí, además, un problema metodológico respecto a la arqueología forense y las posibilidades de hallazgo. En el caso de masacres masivas, el desarrollo de búsquedas individualizadas y a pedido, es de alcance limitado y más costoso. Muchos de los casos de desaparición y ejecución implicaron la muerte de más de una persona al mismo tiempo y además, generalmente no se sabe adónde se encuentran enterradas. Esto obliga a buscar a todas las víctimas de un hecho de desaparición y no sólo al denunciado; en el camino de la investigación se va también conociendo el destino de muchas otras víctimas ligadas o no al mismo caso. Considerando que la Ley abre la posibilidad de que el Estado español elabore los planes generales y destine subvenciones para realizar exhumaciones, se plantea la necesidad de elaborar un Plan Nacional de Búsqueda de Personas Desaparecidas más amplio que los planes de búsqueda individuales. Es un tema fundamental para poder abordar la responsabilidad del Estado con respecto a las víctimas.

El Artículo 13 organiza la prospección arqueológica en función a la autorización de excavaciones arqueológicas previstas en la Ley de Patrimonio Histórico. Se trata, de controlar el estándar científico adecuado de dichas intervenciones. Lo ideal es, como se viene dando, que estas intervenciones sean hechas principalmente por equipos forenses independientes, procedentes de la sociedad civil y que no estén sujetos a ningún tipo de presión política o ideológica. Esto no excluye para nada la participación de los equipos forenses de las instituciones públicas, léase institutos de medicina legal oficiales, siempre y cuando sus intervenciones puedan ser de algún modo observadas por la sociedad en su conjunto y que no sean los únicos peritos válidos, tentación política de gobiernos o autoridades que buscan mantener la impunidad, como aún sucede en el Perú.

La Ley (Artículo 13.1) define la participación en la exhumación a una autoridad judicial aunque sólo en el momento de producirse los hallazgos, los cuales "se pondrán inmediatamente en conocimiento de las autoridades administrativas y judiciales competentes". En realidad, la participación de fiscales o jueces debe acompañar todo el proceso de la intervención arqueológico forense, desde el inicio hasta la identificación de los restos mortales y su devolución a los familiares; es cuando las autoridades judiciales certifican la muerte de la persona y abren instrucción o declaran prescrito el caso, extienden el certificado de defunción para su inscripción en registros civiles. Igualmente, es la autoridad judicial quien debiera validar, en actas, la actuación de los equipos especializados, independientes $\mathrm{u}$ oficiales. Las intervenciones arqueológicas forenses son por definición siempre parte de un proceso judicial.

El Artículo 13 regula también los casos de oposición de alguno de los familiares de las víctimas de la fosa a su exhumación y traslado, aunque no desde una óptica científica. Es una decisión técnica y no individual o política el exhumar todos los cuerpos de una fosa. Cuando la fosa es múltiple, el proceso de identificación antropológica física se realiza sobre el conjunto de restos mortales individualizados hallados en ella. Muchas veces esta tarea es posible hacerla solamente en el ambiente de un laboratorio, sea este en un inmueble o se trate de una morgue de campo y para ello, es necesario que todos los esqueletos de la fosa sean exhumados y analizados. No se puede recuperar algunos cuerpos y a otros no.

Pero además, ningún entierro con restos humanos puede permanecer fuera de un cementerio - a menos que sea arqueológico- por razones de policía sanitaria mortuoria y temas legales. Más allá de la voluntad de los familiares, es duro pero es así, la exhumación debiera ser cumplida. Es 


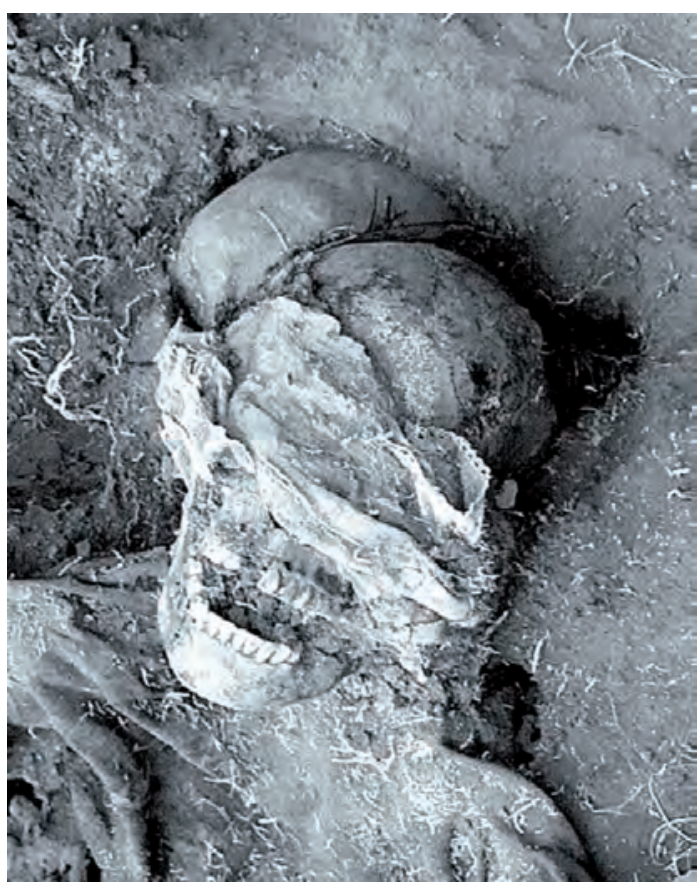

Figura 3. Restos de víctima encontrado en una fosa por arqueologos forenses en base militar peruana.

el Juez o Fiscal, según necesidad de investigación y de aplicación de la ley, en este caso la mencionada, quien debe declarar la necesaria exhumación de los restos. Son las autoridades, los investigadores o los especialistas en acompañamiento psicosocial quienes deben respetuosamente explicar dichas razones a los deudos de la víctima. El artículo 13, inciso 3, de la Ley debe ser reformulado y actualizado en base a estas regulaciones legales también. El acompañamiento psicosocial debe estar siempre presente.

Es necesario señalar que, en los casos de cuerpos no reclamados, de los que no han podido ser identificadas o que no se pueden hallar a sus familiares, la cadena de custodia debe siempre garantizar las condiciones de conservación a que estén sujetos los restos óseos y su integridad física hasta que se realicen las identificaciones. Los restos mortales de las víctimas se constituyen de forma necesaria en evidencia criminal y su trato está sujeto a la normativa legal respecto al manejo de las evidencias judiciales. En ese sentido, a pedido de las partes, los restos mortales siempre pueden ser re-examinados con fines de verificar las identificaciones realizadas o de completar éstas mediante pericias especializadas, ADN por ejemplo.

\section{El PROTOCOLO DE EXHUMACIONES Y LOS "MAPAS DE FOSAS"}

El artículo 12 se refiere al protocolo de exhumaciones y los mapas de fosas. Como se ha dicho líneas arriba, el protocolo de exhumaciones es el último eslabón de la cadena de manuales para asegurar una calidad adecuada y los estándares académicos de la investigación. Su uso debiera estar sujeto al plan general de búsqueda y el plan de intervenciones arqueológicas forenses.

$\mathrm{Al}$ momento, circula una propuesta en borrador del protocolo de exhumaciones (Texto del borrador de protocolo sobre exhumaciones de víctimas del franquismo elaborado por el Gobierno en colaboración con todas las Administraciones Públicas, publicado por el Equipo NIZKOR). Está organizado en tres partes: texto introductorio, solicitudes de exhumación y procedimientos de actuación. En términos generales, el protocolo cumple su función fiel a la Ley, por eso se centra en las exhumaciones y en sus planes individuales, caso por caso, condicionados a los pedidos de los familiares. Algunas ampliaciones y precisiones deben ser debatidas y promovidas a este documento:

a) La memoria biológica y social de las víctimas permite devolver la identidad a los cuerpos presentes en una fosa. Asistimos a la acelerada desaparición física de quienes vieron por última vez a las víctimas y recuerdan información importante para su identificación antropológica física. Se requiere salir de la visión del "caso por caso" y realizar campañas masivas y urgentes de recolección de información Antemortem, alimentando bases de datos especializadas que garanticen la información hasta el eventual hallazgo de cualquiera de las víctimas. Se trata de un 
tema estratégico, requiere de un plan general y de un preciso protocolo de actuación, aun ausente.

b) La autorización de exhumación se tramita ante la autoridad autonómica y ante las autoridades locales y no ante el juez. Esto suma una serie de vías burocráticas que complican la tramitación la cual, finalmente, recae en el familiar. Ante esto, se deben crear juzgados especializados, tal como ocurre en otros países, que lleven adelante los procesos con conocimiento de causa, con experiencia acumulativa y cada vez más expeditivos, evitando la sobrecarga de otros juzgados no especializados. La autoridad judicial tiene el poder de autorización total, sea adonde sea que el sitio de entierro se encuentre si las causas lo justifican. El arqueólogo forense debe estar autorizado por la autoridad judicial.

c) El protocolo deja a criterio de los gobiernos autónomos la decisión de exhumar o no cuando hay oposición por una parte de los familiares. Pero, las características del trabajo arqueológico forense impiden hacer exhumaciones parciales, peor cuando se requiere búsquedas masivas. Esto, sin olvidar las obligatorias medidas de sanidad ya mencionadas respecto a los entierros fuera de cementerios y otras regulaciones legales.

d) Se establece el concurso de equipos especializados que hayan sido constituidos hasta antes del 1 de junio del 2004, pero más que la antigüedad se trata que los miembros del equipo demuestren la experiencia requerida. Se debe fomentar la participación y creación de más equipos especializados, especialmente por la gran magnitud de la tarea y no limitarlos por su fecha de creación.

El artículo 13 incluye también la propuesta de realizar el mapa de fosas (Artículo 13.2); es un gran avance, pero sólo si estos pueden ir

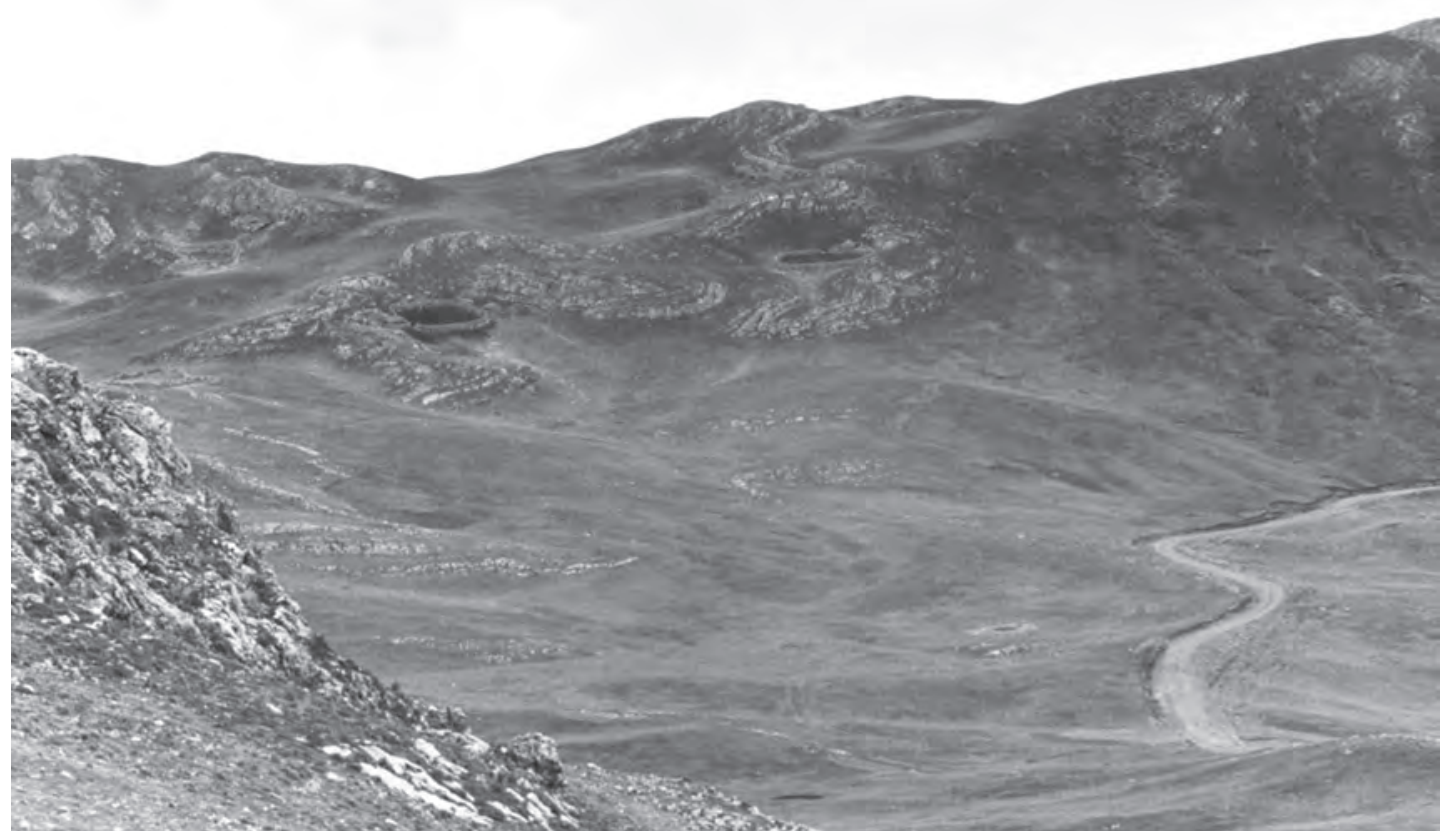

Figura 4. Paraje con fosas comunes en Ayacucho que requiere intervención regulada de arqueólogos forenses. 
más allá de la pura función administrativa, es decir, más allá de la tramitación y delimitación de terrenos. Los mapas sirven para hallar a las personas desaparecidas, es este el objetivo que da sentido a este tipo de instrumentos. Un mapa de fosas inteligente debe servir para el desarrollo de búsquedas complejas (ia quiénes y a cuántos buscamos, adónde están, a cuántos podremos rescatar, a cuántos ya no podremos encontrar jamás, a quiénes y a cuántos podríamos encontrar pronto, a cuántos en el futuro?) que permitan ir progresivamente solucionando el problema de los desaparecidos españoles en plazos y números más o menos esperables.

\section{Diez Reflexiones finales ACERCA de la Ley de Memoria Histórica}

1) La ley debe enfatizar la obligación del Estado español en la búsqueda de los desaparecidos. Esta responsabilidad no puede caer solamente en las solicitudes de las familias o de las asociaciones. Es necesario cumplir con las normas internacionales de los derechos humanos y los requerimientos científicos básicos.

2) Se debe plantear la elaboración de un "plan general de búsqueda de los desaparecidos" impulsado por el Estado, con la participación de las autoridades públicas pertinentes y de la sociedad civil, especialmente de las representaciones de los grupos de afectados. No se debe depender exclusivamente de las iniciativas de grupos de familiares o de sus asociaciones representativas, aunque estas deben ser necesariamente incorporadas en dicho plan.

3) Del plan anterior, se desprende el "plan de intervenciones arqueológicas forenses" que permita programar las intervenciones en un calendario. En este plan se debe incluir el Protocolo de Intervenciones Arqueológicas Forenses (entendiendo estas al conjunto de las actuaciones) y no solamente un "protocolo de exhumaciones". El actual Texto del borrador de protocolo sobre exhumaciones de víctimas del franquismo elaborado por el Gobierno en colaboración con todas las Administraciones Públicas debe ser ampliado.

4) El plan general de búsqueda de personas desaparecidas debe incluir también la realización de un registro Antemortem permanente que asegure la memoria biológica y social de las víctimas ante su eventual hallazgo en un futuro cercano o lejano. Actualmente esta memoria está en serio riesgo de desaparición física total y sin ella, sería imposible la identificación de los restos de las víctimas y la devolución de su identidad.

5) Los restos mortales de las víctimas enterradas en fosas comunes o individuales fuera de los cementerios oficiales no pueden permanecer allí de ningún modo pues el actual ordenamiento legal (policía sanitaria y mortuoria) no debiera permitirlo. Todas las personas, si no son cremadas, deben estar inhumadas en un cementerio.

6) Todas las exhumaciones se hacen sobre el total de las personas que el sitio de entierro pueda contener. No se pueden admitir exhumaciones parciales.

7) Los registros de entierros en cementerios católicos o de cualquier otra confesión, así como los registros en cementerios públicos bajo las administraciones locales, son documentos y archivos que deben ser considerados de interés público y estar abiertos a las investigaciones que tengan por objeto la búsqueda de las personas desaparecidas.

8) Los actuales trámites de autorización de exhumaciones ante un número variable de instancias deben reducirse a dos: la orden judicial y la aprobación del proyecto científico por las autoridades pertinentes según la Ley de Patrimonio Cultural.

9) Todos los restos mortales de personas víctimas de desaparición forzada y ejecución extrajudicial deben ser consideras como evidencias de crímenes cometidos y requieren de intervención judicial para declarar la 
prescripción si es el caso o para la realización de algún tipo de diligencia o proceso de ésta índole. De otro modo, los arqueólogos forenses que recuperan estos restos pueden ser sujetos de acusaciones de alteración o de destrucción de evidencia judicial.

10) Las acciones de búsqueda deben centralizarse en una Oficina Para Personas Desaparecidas que podría estar incluida dentro de la Oficina de Atención a las Víctimas planteadas en el Plan de Derechos Humanos del Gobierno de España en la medida № 87.

\section{Palabras finales}

La intención de este artículo es la de reflexionar, a partir del análisis de la Ley de Memoria Histórica actualmente vigente en España, acerca de las secuelas de las violencia del conflicto interno peruano y la necesidad de abordar integralmente el problema de los desaparecidos y los ejecutados extrajudicialmente, de los sitios de entierro clandestinos, y de los lugares de memoria para las víctimas. Esperamos poder aportar una guía de discusión para las soluciones legislativas desde el Estado peruano a la problemática de las familias de los aproximadamente 15 mil desaparecidos producto de nuestro conflicto interno y en la que aun no hemos desarrollado un proceso político, jurídico - legal, humanitario y científico acorde al reclamo de éstos por recuperar a sus seres queridos y a la necesidad del Perú y de los peruanos de dignificar sus paisajes, es decir, paisajes sin fosas comunes que sean la memoria que garantice la no repetición. Los arqueólogos forenses peruanos tienen una gran tarea presente. 